\title{
On the Measurement of Priming: What is the Correct Baseline?
}

\author{
Endel Tulving \\ Rotman Research Institute, Baycrest Centre, North York, Ontario, Canada

\section{C.A. Gordon Hayman} \\ Department of Psychology, Lakehead University, Thunder Bay, Ontario, \\ Canada
}

\begin{abstract}
We argue, contrary to Ostergaard (this issue), that the baseline for measuring priming effects in "recognition/identification" experiments is correctly estimated by the subjects' performance with non-primed items. There is no reason to assume, as Ostergaard (this issue) does, that priming that occurs in a single presentation of the target item is qualitatively different from priming that occurs, in the same experimental situation, in two or more presentations, or that empirical findings, such as stochastic independence between recognition and primed identification, are affected by the number of presentations of the target items at study.
\end{abstract}

\section{INTRODUCTION}

In the protracted debate about the use of contingency analyses of data of implicit and explicit tests of memory, spelled out in exhausting detail in papers such as those by Shimamura (1985), Hayman and Tulving (1989a; 1989b), Hintzman and Hartry (1990), Ostergaard (1992; this issue) and Tulving and Hayman (1993), the latest scuffle focuses on the problem of how one should measure priming.

The problem has arisen in connection with Ostergaard's (1992) Maximum Memory Dependence (MMD) model as a contrast to the Stochastic

Requests for reprints should be addressed to Endel Tulving, Rotman Research Institute, Baycrest Centre, 3560 Bathurst Street, North York, Ontario M6A 2E1, Canada. E-mail: tulving@psych.toronto.edu.

We thank Henry L. Roediger III for constructive suggestions. The authors' research is supported by Natural Sciences and Engineering Research Council of Canada Grants Nos A8632 (E.T.) and OGP46356 (C.A.G.H.) 
Independence (SI) model that had been used exclusively previously. In applying the MMD model to published data, Ostergaard adopted an unusual baseline - the "test-primed baseline"-for measuring the amount of priming. Like everyone else who had ever done any priming experiments, we thought, and still think, that priming should be measured in terms of the difference between primed and non-primed items. In his 1992 paper, however, Ostergaard measured priming in terms of the difference between two kinds of primed performance, those designed as "testprimed" and "study-test primed" by Tulving, Schacter and Stark (1982, fig. 2). ${ }^{1}$ Thus, when using MMD, priming is not what it has always been, it is the difference between some priming and a little more of it.

In an earlier report (Tulving \& Hayman, 1993), we thought Ostergaard (1992) had made a novel and important contribution with his MMD model. Now we see from his reply to our article (Ostergaard, this issue) that he was actually trying to make two important contributions in his article: the MMD model and his new definition of priming that no-one had ever used before. Like the two kinds of tests under consideration, however, his first contribution was explicit, whereas the second was most decidedly implicit. Ostergaard (this issue) tells us that: "During the development of the MMD model, considerable thought was given to the question of what would constitute the most appropriate estimate of priming effects...". But he also must have given considerable thought to the problem of how to keep his thoughts about how to measure priming in MMD from being discovered by the readers. As best as we can tell, he adopted the following strategy for keeping the readers from realising that a revolution in the measurement of priming was afoot:

1. Define priming conventionally, like everyone else: "In priming tasks such as identifying briefly presented words, word fragments, or fragmented pictures, subjects perform better with items presented earlier than with new items, and this difference between previously studied and new items is the priming effect" (Ostergaard, 1992, p. 413, emphasis added). Given the conventional definition, readers are less likely to suspect anything new.

2 . Let the reader think that "previously studied" items are those that appeared in the study list and "non-studied" items are those that did not appear in the study list. This is best achieved by not telling, or reminding, the reader that priming can occur even when an item is not being inten-

\footnotetext{
'Ostergaard's new term for test-primed items is "RN-NEW" or "New at Test 1", and his new term for study-and-test primed items is "old", "Study" or "Study+Test-1 primed". The principle here seems to be: (a) why use old terms when new ones will do?, or (b) a little healthy variety in terminology will keep the readers' minds sharp, or (c) both.
} 
tionally studied, as, for instance, when a word is presented as a distractor in a recognition test (Tulving et al., 1982), and that such distractors have been primed by the time they appear in the identification test.

3. Never mention the concept of "test priming" or the existence of "test-primed" items under whatever terms! This may give the game away! Throughout the paper refer only to "studied" and "non-studied" items. Identification of "non-studied" and "new" items also helps.

4. Do not say explicitly, anywhere in the paper, that a new measure of priming is being introduced. Given that everybody knows that priming is measured in terms of the comparison of primed performance with non-primed baseline, readers are unlikely to suspect a revolutionary departure from the tradition unless their attention is forcefully directed to it. Therefore, do not draw their attention to it!

5. Write as if baseline identification performance included only one of the two components, the "non-memory" component. This can be done best by writing an equation; readers are usually impressed with such formality, and are therefore unlikely to wonder how it is possible for testprimed items, used as the "non-studied" baseline, not to include any "memory" component. This is important, because if the readers figure out that both the "non-studied" baseline and the "studied" performance include both "memory" and "non-memory" components, the MMD model, as presented, does not make sense and they may start wondering what is going on.

Ostergaard carried out this plan brilliantly, and in consummate detail. As a result of this plan, his second contribution-the new procedure for measuring priming in "recognition/identification" experiments-remained concealed from just about everybody. ${ }^{2}$ Now, however, that the cat is out of the bag, we have to come to grips with it. What should we make of his suggestion?

\section{WHAT IS THE CORRECT BASELINE?}

Ostergaard's newly revealed justification of the test-primed baseline is based on one central idea: The "memory" components that enter into the contingency relation between priming and explicit memory must be attributable to a single study episode, the "original study episode" (Ostergaard, this issue, p. 6). He does not provide any reasons for this curious choice

\footnotetext{
${ }^{2}$ We were mistaken in our assertion that in the concrete example that Ostergaard presented to illustrate his MMD model he used the non-primed baseline (Tulving \& Hayman, 1993. footnote 4).
} 
other than a few questionable, out-of-context, quotes from the "proponents" of contingency analyses.

We find this choice odd, for several reasons, some of which we have already mentioned, such as Ostergaard's own definition of the "priming effects", and the fact that the performance with test-primed items also includes a "memory" component. More important, however, is the fact that the relevant issue has always been the relation between the processes underlying performance changes on implicit and explicit tests of memory, rather than consequences of a single study episode. The title of the initial Tulving et al. (1982) study, "Priming effects in word-fragment completion are independent of recognition memory", reflects the orientation. Nowhere in that paper was there any mention of the single or original study episode. Nor did the concept of a "single study episode" occur anywhere in the discussion of early studies of priming in Tulving (1983). Indeed, tying the phenomenon of priming to a single study episode would have been absurd, given that the seminal studies by Warrington and Weiskrantz $(1968 ; 1970)$ with amnesic patients, which inspired the Tulving et al. (1982) study with normal subjects, had used multiple study trials. In many subsequent experiments, too, multiple study trials have routinely been used (e.g. Challis \& Sidhu, 1993; Graf, Squire, \& Mandler, 1984; Greene, 1986; Musen \& Treisman, 1990; Parkin, Reid, \& Russo, 1990; Schacter et al., 1991; for a review, see Roediger \& McDermott, 1993).

The point is this. There is no rational or empirical reason to assume, as Ostergaard (this issue) does, that priming that occurs as a result of a single experimental exposure of the target item is qualitatively different from multiple-exposure priming, or that empirical findings, such as stochastic independence between recognition and primed identification, are affected by the number of presentations of the target items at study. It is possible, of course, that they do. But verification of such a state of affairs is better achieved through experiment than assertion.

A key ingredient in Ostergaard's argument against the conventional baseline is his thought experiment in which the retention interval in the "recognition/identification" experiment is stretched to many years. Its anticipated results, he says, would lead to "bizarre conclusions". Although we are great fans of thought experiments and believe in their value, we have reservations about this one. After a very long retention interval, subjects' recognition performance is going to be on or near the "floor", and experiments producing data on the "floor" are not very informative. Good scientists do not do such experiments. By the logic of Ostergaard's (1992) own MMD model, too, it is not possible to discriminate between the predictions of the MMD model and the SI model in a situation in which the "memory" component of one test (here, recognition) is or approaches zero. The fact that "test-priming" effects are likely to be well above zero is irrelevant. 
In summary, Ostergaard's (this issue) concept of the "original study episode" is a red herring. There is no rational reason to expect that the quiddity of priming, including its relation to other forms of learning, should depend on the number of study episodes. If it could be shown empirically that the relation between priming and other forms of learning changes across study trials, it would constitute interesting news. But in the absence of such evidence, restricting the study of the nature of priming to priming produced by the original study episode makes no sense.

Manuscript received July 1994

\section{REFERENCES}

Challis, B.H., \& Sidhu, R. (1993). Dissociative effect of massed repetition on implicit and explicit measures of memory. Journal of Experimental Psychology: Learning, Memory and Cognition, 19, 115-127.

Graf, P., Squire, L.R., \& Mandler, G. (1984). The information that amnesic patients do not forget. Journal of Experimental Psychology: Learning, Memory and Cognition, 10 , 164-178.

Greene, R.L. (1986). Word stems as cues in recall and completion tasks. Quarterly Journal of Experimental Psychology, 38A, 663-673.

Hayman, C.A.G., \& Tulving, E. (1989a). Contingent dissociation between recognition and fragment completion: The method of triangulation. Journal of Experimental Psychology: Learning, Memory and Cognition, 15, 229-240.

Hayman, C.A.G., \& Tulving, E. (1989b). Is priming in fragment completion based on a "traceless" memory system? Journal of Experimental Psychology: Learning, Memory and Cognition, 15, 941-956.

Hintzman, D.L., \& Hartry, A.L. (1990). Item effects in recognition and fragment completion: Contingency relations vary for different subsets of words. Journal of Experimental Psychology: Learning, Memory and Cognition, 16, 995-969.

Musen, G., \& Treisman, A. (1990). Implicit and explicit memory for visual patterns. Journal of Experimental Psychology: Learning, Memory and Cognition, 16, 127-137.

Ostergaard, A. (1992). A method for judging measures of stochastic independence: Further comments on the current controversy. Journal of Experimental Psychology: Learning, Memory and Cognition, 18, 413-420.

Parkin, A.J., Reid, T.K., \& Russo, R. (1990). On the differential nature of implicit and explicit memory. Memory and Cognition, 18, 507-514.

Roediger, H.L., III, \& McDermott, K.B. (1993). Implicit memory in normal human subjects. In F. Boller \& J. Grafman (Eds), Handbook of neuropsychology, pp. 63-131. Amsterdam: Elsevier.

Schacter, D.L., Cooper, L.A., Delaney, S.M., Peterson, M.A., \& Tharan, M. (1991). Implicit memory for possible and impossible subjects: Constraints on the construction of structural descriptions. Journal of Experimental Psychology: Learning, Memory and Cognition, 17, 3-19.

Shimamura, A.P. (1985). Problems with the finding of stochastic independence as evidence for multiple memory systems. Bulletin of the Psychonomic Society, 23, 506-508.

Tulving, E. (1983). Elements of episodic memory. Oxford: Clarendon Press.

Tulving, E., \& Hayman, C.A.G. (1993). Stochastic independence in the recognition/ identification paradigm. European Journal of Cognitive Psychology, 5, 353-374. 
Tulving, E., Schacter, D.L., \& Stark, H.A. (1982). Priming effects in word-fragment completion are independent of recognition memory. Journal of Experimental Psychology: Learning, Memory and Cognition, 8, 352-373.

Warrington, E.K., \& Weiskrantz, L. (1968). New method of testing long-term retention with special reference to amnesic patients. Nature, 217, 972-974.

Warrington, E.K., \& Weiskrantz, L. (1970). Amnesic syndrome: Consolidation or retrieval? Nature, 228, 629-630. 